\title{
Hard and elastic epitaxial ZrB2 thin films on Al2O3(0001) substrates deposited by magnetron sputtering from a ZrB2 compound target
}

Lina Tengdelius, Esteban Broitman, Jun Lu, Fredrik Eriksson, Jens Birch, Tomas Nyberg, Lars Hultman and Hans Högberg

\section{Linköping University Post Print}

\section{Tweet}

N.B.: When citing this work, cite the original article.

Original Publication:

Lina Tengdelius, Esteban Broitman, Jun Lu, Fredrik Eriksson, Jens Birch, Tomas Nyberg, Lars Hultman and Hans Högberg, Hard and elastic epitaxial ZrB2 thin films on Al2O3(0001) substrates deposited by magnetron sputtering from a ZrB2 compound target, 2016, Acta Materialia, (111), , 166-172.

http://dx.doi.org/10.1016/j.actamat.2016.03.064

Copyright: Elsevier

http://www.elsevier.com/

Postprint available at: Linköping University Electronic Press

http://urn.kb.se/resolve?urn=urn:nbn:se:liu:diva-128612 


$$
\text { c) }(7)(9)
$$




\title{
Hard and elastic epitaxial $\mathrm{ZrB}_{2}$ thin films on $\mathrm{Al}_{2} \mathrm{O}_{3}(0001)$ substrates deposited by magnetron sputtering from a $\mathrm{ZrB}_{2}$ compound target
}

\author{
Lina Tengdelius, ${ }^{1 *}$ Esteban Broitman, ${ }^{1}$ Jun Lu, ${ }^{1}$ Fredrik Eriksson, ${ }^{1}$ Jens Birch, ${ }^{1}$ \\ Tomas Nyberg, ${ }^{2}$ Lars Hultman, ${ }^{1}$ and Hans Högberg ${ }^{1}$ \\ ${ }^{1}$ Thin Film Physics Division, Department of Physics, Chemistry, and Biology (IFM) \\ Linköping University, SE-581 83 Linköping, Sweden. \\ ${ }^{2}$ Department of Solid State Electronics, Uppsala University \\ Box 534, SE-751 21 Uppsala, Sweden
}

\begin{abstract}
*Corresponding author: E-mail address: lina.tengdelius@liu.se. Phone number: +4613286692
E-mail addresses for co-authors: esteban.broitman@liu.se, jun.lu@liu.se, fredrik.eriksson@liu.se,_ jens.birch@liu.se,__tomas.nyberg@angstrom.uu.se, lars.hultman@liu.se, hans.hogberg@liu.se
\end{abstract}

\begin{abstract}
Zirconium diboride $\left(\mathrm{ZrB}_{2}\right)$ exhibits high hardness and high melting point, which is beneficial for applications in for e.g. metal cutting. However, there is limited data on the mechanical properties of $\mathrm{ZrB}_{2}$ films and no data on epitaxial films. In this study, $\mathrm{ZrB}_{2}(0001)$ thin films, with thicknesses up to $1.2 \mu \mathrm{m}$, have been deposited on $\mathrm{Al}_{2} \mathrm{O}_{3}(0001)$ substrates by direct current magnetron sputtering from a compound target. X-ray diffraction and transmission electron microscopy show that the films grow epitaxially with two domain types exhibiting different inplane epitaxial relationships to the substrate. The out-of-plane epitaxial relationship was determined to $\mathrm{ZrB}_{2}(0001) \| \mathrm{Al}_{2} \mathrm{O}_{3}(0001)$ and the in-plane relationships of the two domains to $\mathrm{ZrB}_{2}[10 \overline{1} 0] \| \mathrm{Al}_{2} \mathrm{O}_{3}[10 \overline{1} 0]$ and $\mathrm{ZrB}_{2}[11 \overline{2} 0] \| \mathrm{Al}_{2} \mathrm{O}_{3}[10 \overline{1} 0]$. Mechanical properties of the films,
\end{abstract}


evaluated by nanoindentation, showed that all films exhibit hardness values above 45 GPa, a reduced Young's modulus in the range 350-400 GPa, and a high elastic recovery of $70 \%$ at an applied load of $9000 \mu \mathrm{N}$.

Keywords: Borides, Epitaxial growth, Mechanical properties, Nanoindentation, Sputter deposition

\section{Introduction}

Early transition metal diborides are ceramic materials that, like early transition metal carbides and nitrides, demonstrate high melting points, high hardness values, chemical inertness, and good wear and corrosion resistance [1,2]. However, some properties of the diborides differ from those of the carbides and nitrides. The larger size of the $\mathrm{B}$ atom compared to $\mathrm{C}$ and $\mathrm{N}$ atoms is reflected in their crystal structures; the hexagonal $\mathrm{AlB}_{2}$ type is seen for the diborides with the $\mathrm{B}$ atoms in triagonal prismatic interstitials, whereas the $\mathrm{NaCl}$ structure with filling of $\mathrm{C} / \mathrm{N}$ in octahedral sites is typically found for the carbides and nitrides. In addition, B has a smaller number of valance electrons available for chemical bonding as well as a lower electronegativity value than $\mathrm{C}$ and $\mathrm{N}$. Thus, the electronic properties of B combined with the symmetry of the $\mathrm{AlB}_{2}$ structure affect the bonding in the diborides to give them more metallic character compared to carbides and nitrides, which is beneficial for development of hard but less brittle materials used in, e.g., metal cutting.

The literature shows that the mechanical properties of diboride bulk and thin films have been studied to a much lesser extent than the carbides and nitrides, used extensively in the metal cutting industry today. Among the diborides, titanium diboride $\left(\mathrm{TiB}_{2}\right)$ has attracted the most interest mainly due to its use in machining of aluminum, while e.g., zirconium diboride $\left(\mathrm{ZrB}_{2}\right)$ has attracted little interest. Studies on bulk materials reveal similar hardness values for $\mathrm{TiB}_{2}$ and $\mathrm{ZrB}_{2}$ with $24 \mathrm{GPa}$ [3] and $23 \mathrm{GPa}$ [1], respectively, suggesting that $\mathrm{ZrB}_{2}$ is a suitable 
material to rival $\mathrm{TiB}_{2}$ in metal cutting. For thin films, there is a large spread in hardness. $\mathrm{TiB}_{2}$ range from 15 to $70 \mathrm{GPa}$ [4-10] and $\mathrm{ZrB}_{2}$ exhibits a spread in hardness values between $16 \mathrm{GPa}$ and $5480 \mathrm{HV}$ ( $54 \mathrm{GPa}$ ) [11-13], determined from a small number of studies. The scarce data available in the literature for mechanical properties of $\mathrm{ZrB}_{2}$ films, and the limited comparison to film microstructure as well as the lack of results from epitaxial films, warrants this study.

$\mathrm{ZrB}_{2}$ thin films are typically synthesized by sputtering from a compound or composite target [12,14-21]. However, sputtering from compound targets introduces complexity to the process, owing to the different physical properties of the two elements, resulting in films that are usually non-stoichiometric $[17,22]$ and/or have a high level of contaminants $[14,17,18,22,23]$. For direct current magnetron sputtering (DCMS) from $\mathrm{ZrB}_{2}$ compound targets, we have previously presented a synthesis route for growth of stoichiometric films with a low level of contaminants [20], including epitaxial growth on $\mathrm{Si}(111)$ and $4 \mathrm{H}-\mathrm{SiC}(0001)$ [21,24].

In this study, we used our previous development of DCMS of $\mathrm{ZrB}_{2}$ thin films to investigate epitaxial growth of $\mathrm{ZrB}_{2}$ thin films on $\mathrm{Al}_{2} \mathrm{O}_{3}(0001)$ substrates. The mechanical properties of these films were then evaluated by nanoindentation. $\mathrm{Al}_{2} \mathrm{O}_{3}$ was chosen as the substrate material due to its suitable lattice match with $\mathrm{ZrB}_{2}$ and because it has sufficient mechanical hardness to enable reliable measurements of the film's mechanical properties.

\section{Experimental details}

$\mathrm{ZrB}_{2}$ thin films were deposited by a DCMS process described recently [21,24] onto $\mathrm{Al}_{2} \mathrm{O}_{3}(0001)$ substrates. All films were deposited using a sputtering power of $400 \mathrm{~W}$ at a temperature of $900{ }^{\circ} \mathrm{C}$ and the substrate held at floating potential. The applied deposition times were $5 \mathrm{~min}$ and $15 \mathrm{~min}$, yielding layer thicknesses of about 400 and $1200 \mathrm{~nm}$, respectively. Prior to deposition, the substrates were degreased in 5 min sequential ultrasonic baths of trichloroethylene, acetone and isopropanol, and blown dry with pure nitrogen. 
X-ray diffraction (XRD) $\theta / 2 \theta$ scans were performed to determine the structural properties of the $\mathrm{ZrB}_{2}$ films, using a Philips PW1820 diffractometer equipped with a $\mathrm{Cu} \mathrm{K \alpha}$ source operated at $40 \mathrm{kV}$ and $40 \mathrm{~mA}$. XRD pole figures and reciprocal space maps (RSM, as described in refs $[25,26])$ were measured with a PANalytical EMPYREAN diffractometer at $45 \mathrm{kV}$ and $40 \mathrm{~mA}$. RSM of the symmetrical 0002 and the asymmetrical $10 \overline{1} 3 \mathrm{ZrB}_{2}$ peaks were used to determine the lattice parameters of the films. The maps were recorded as consecutive coupled $\theta / 2 \theta$ scans, each separated by an $\omega$ offset. The strain was assessed by using the following formulas:

In-plane strain: $\quad \varepsilon_{a}=\frac{a_{m e a s}-a_{0}}{a_{0}}$

Out-of-plane strain: $\quad \varepsilon_{c}=\frac{c_{\text {meas }}-c_{0}}{c_{0}}$,

where $\mathrm{a}_{0}, \mathrm{c}_{0}$ are the literature values of the $a$ and $c$ axes, i.e. $3.1687 \AA$ and $3.5300 \AA$ respectively, and $\mathrm{a}_{\text {meas }}$ and $\mathrm{c}_{\text {meas }}$ are the corresponding measured axis values, extracted from the RSM.

Transmission electron microscopy (TEM) imaging, of cross-sections of the films, was carried out by using a FEI Tecnai G2 TF20 UT HRTEM with a field emission gun operated at $200 \mathrm{kV}$. The cross-sectional TEM specimens were prepared by gluing two pieces of samples face to face together, polishing from both sides of the specimen down to $60 \mu \mathrm{m}$ in thickness, and finally ion milling to electron transparency. Scanning transmission electron microscopy (STEM) imaging of the film surface and electron energy loss spectroscopy (EELS) was performed using a double corrected Cs FEI Titan 3 microscope operated at $300 \mathrm{kV}$. The plan view specimens for STEM were manufactured by polishing the substrate from the back side down to $50 \mu \mathrm{m}$ and ion milling from the substrate side until the sample was electron transparent.

The hardness $(\mathrm{H})$ and reduced Young's modulus $\left(\mathrm{E}_{\mathrm{r}}\right)$ as well as the elastic recovery $\left(\mathrm{W}_{\mathrm{e}}\right)$ were investigated using a Hysitron Triboindenter TI950 instrument. The nanoindentations were 
conducted using a Berkovich diamond probe at applied loads in the range 500-10000 $\mu \mathrm{N}$. In the indentation experiments, the penetration depth of the indenter was kept lower than $10 \%$ of the film thickness to avoid influence from the substrate. $\mathrm{H}$ and $\mathrm{E}_{\mathrm{r}}$ were calculated by the method of Oliver and Pharr using the unloading elastic part of the load-displacement curve [27]. $\mathrm{W}_{\mathrm{e}}$ was calculated as:

$W_{e}=100 \times \frac{\left(h_{m}-h_{f}\right)}{h_{m}}$,

where $h_{m}$ is the maximum penetration depth (produced at the maximum indentation load) and $\mathrm{h}_{\mathrm{f}}$ corresponds to the final displacement after complete unloading. $\mathrm{W}_{\mathrm{e}}$ is calculated taking into account both elastic and plastic deformations, and results are closely related to the work of indentation [28]. To be able to relate Vickers hardness values reported by others to our values given in GPa, an approximate conversion of the Vickers hardness values to GPa were made by

multiplying the Vickers hardness values by 0.009807 , i.e. converting $\mathrm{kg} / \mathrm{mm}^{2}$ to $\mathrm{Pa}$. The exact conversion from a Vickers hardness into the nanoindentation hardness values needs a geometrical factor correction which is $\sim 0.927$ for a perfect Berkovich diamond. Scanning probe microscopy (SPM) images were obtained using the nanoindenter Berkovich diamond probe raster scanned at $0.5 \mathrm{~Hz}$ on areas of $5 \mathrm{x} 5 \mu \mathrm{m}$ size across the surface of the sample.

The electrical resistivity values of the films were calculated from measured sheet resistivity data determined from four point probe measurements with a CMT-SR200N instrument from Advanced Instrument Technology and using the film thicknesses from TEM images.

\section{Results and Discussion}

\subsection{Characterization of fundamental film properties}

Fig. 1 shows a $\theta / 2 \theta$ diffractogram obtained from a $\mathrm{ZrB}_{2}$ film deposited on $\mathrm{Al}_{2} \mathrm{O}_{3}(0001)$ for $15 \mathrm{~min}$, yielding a film thickness of $\sim 1200 \mathrm{~nm}$. The diffractogram shows peaks of high 
intensities at $2 \theta$ angles of $25.2^{\circ}, 51.8^{\circ}, 81.7^{\circ}$, and $121.5^{\circ}$. These are the $0001,0002,0003$, and 0004 peaks of the $\mathrm{ZrB}_{2}$ phase. Other peaks visible in the diffractogram are 0006 and 00012 of the $\mathrm{Al}_{2} \mathrm{O}_{3}$ substrate at $2 \theta$ angles $41.7^{\circ}$ and $90.6^{\circ}$ as well as a weak $\mathrm{ZrB}_{2} 10 \overline{1} 0$ peak at $2 \theta \approx 32.7^{\circ}$. This type of diffraction pattern with high intensities of the $\mathrm{ZrB}_{2} 000 \ell$ peaks indicates a large vertical coherence length in the film, i.e. the film is well-ordered from the substrate to the film-vacuum interface. It is also in accordance with our previous results, demonstrating epitaxial growth of $\mathrm{ZrB}_{2}$ films on $4 \mathrm{H}-\mathrm{SiC}(0001)$ and $\mathrm{Si}(111)$ substrates $[21,24]$. Furthermore, the inset in Fig. 1 with a linear scale shows that both the 0001 and 0002 peaks from the film are of significantly higher intensities compared to the substrate 0006 and 00012 peaks. Thus, the appearance of the $000 \ell$ peaks from $\mathrm{ZrB}_{2}$ with their high intensities and the fact that no other growth direction is visible in the diffractogram, except for the weak $10 \overline{1} 0$ peak ( $<0.003 \%$ in intensity of the 0001 peak), is a strong indication that $\mathrm{ZrB}_{2}$ grows epitaxially on $\mathrm{Al}_{2} \mathrm{O}_{3}(0001)$. Although, it is possible that the strongest peak for non-textured $\mathrm{ZrB}_{2} 10 \overline{1} 1$ at $2 \theta \approx 41.7^{\circ}$ could overlap with the substrate 0006 peak, such growth condition is less likely as the $10 \overline{1} 2$ at $2 \theta \approx 62.5^{\circ}$ peak is absent from the film. Thinner films $(\sim 400 \mathrm{~nm})$ are also $0001-$ oriented, but the $10 \overline{1} 0$ peak is more pronounced, compared to the thicker film in Fig. 1, and the $20 \overline{2} 0$ and $30 \overline{3} 0$ peaks are also visible (diffractograms not shown). In addition, the $11 \overline{2} 1,20 \overline{2} 1$, and $10 \overline{1} 2$ peaks can be seen for some of these films, and the $10 \overline{1} 1$ peak is most likely also present, but overlaps with the 0006 peak from the substrate.

Epitaxial film growth was confirmed by $\{10 \overline{1} 1\}$ pole figure measurements of the $\mathrm{ZrB}_{2}$ samples, as shown in Fig. 2 a) for a typical 1200 nm thick film. 12 elliptically shaped points of high intensities are visible in the pole figure. These features are separated by $30^{\circ}$ in $\phi$ and located at a $\psi$ angle of $\sim 50^{\circ}$, which corresponds well to the angle between the 0001 and $10 \overline{1} 1$ plane in $\mathrm{ZrB}_{2}$ of $52.7^{\circ}$. From the observed six-fold symmetry of the $\mathrm{AlB}_{2}$ crystal structure, the number 
of poles would be six separated by $60^{\circ}$ in $\phi$, so the appearance of 12 points means that there are two domains having different in-plane epitaxial relationships to the substrate. The high intensity in the center of the pole figure originates from the 0006 pole of the substrate. In Fig. 2 b) the $\{10 \overline{1} 4\}$ pole figure of the $\mathrm{Al}_{2} \mathrm{O}_{3}$ substrate can be seen. Three poles separated by $120^{\circ}$ in $\phi$ is seen due to the three-fold symmetry of this crystal plane. From these two pole figures it is possible to determine the out-of-plane epitaxial relationship to $\mathrm{ZrB}_{2}(0001) \| \mathrm{Al}_{2} \mathrm{O}_{3}(0001)$ and the in-plane relationships of the two domains to $\mathrm{ZrB}_{2}[10 \overline{1} 0] \| \mathrm{Al}_{2} \mathrm{O}_{3}[10 \overline{1} 0]$ and $\mathrm{ZrB}_{2}[11 \overline{2} 0] \| \mathrm{Al}_{2} \mathrm{O}_{3}[10 \overline{1} 0]$. For the domain with the epitaxial relationship $\mathrm{ZrB}_{2}[10 \overline{1} 0] \| \mathrm{Al}_{2} \mathrm{O}_{3}[10 \overline{1} 0]$, the $\mathrm{ZrB}_{2}$ crystals are aligned to the $\mathrm{Al}_{2} \mathrm{O}_{3}$ crystal and the growth is actualized by a 3:2 coincidence mismatch of $0.11 \%$ between the $\mathrm{Zr}$ - and the Al-lattices, i.e. 3 unit cells in the Zr-lattice scales with 2 unit cells in the Al-lattice. For the domain with the epitaxial relationship $\mathrm{ZrB}_{2}[11 \overline{2} 0] \| \mathrm{Al}_{2} \mathrm{O}_{3}[10 \overline{1} 0]$, the film lattice is rotated $30^{\circ}$ in the plane with respect to the substrate and the growth proceeds through a 7:8 coincidence mismatch of $0.84 \%$ between the Zr- and the O-lattices. The $400 \mathrm{~nm}$ thick films are also epitaxial, exhibiting the same epitaxial relationships as the thicker films. We note that the epitaxial relationship of one of our domains, $\mathrm{ZrB}_{2}(0001) \| \mathrm{Al}_{2} \mathrm{O}_{3}(0001)$ and $\mathrm{ZrB}_{2}[11 \overline{2} 0] \| \mathrm{Al}_{2} \mathrm{O}_{3}[10 \overline{1} 0]$, is the same as the single epitaxial relationship reported by Bera et al [29] for their films deposited using chemical vapor deposition from the single precursor $\mathrm{Zr}\left(\mathrm{BH}_{4}\right)_{4}$.

It is well known that strain can affect the mechanical properties of a material. Our system could yield epitaxial strain due to mismatch of lattice parameters and thermal expansion coefficients between film and substrate. To evaluate the strain in our films, RSM were recorded. The map of the asymmetric $10 \overline{1} 3$ peak for a $1200 \mathrm{~nm}$ thick film can be seen in Fig. 3. From this map and the map of the symmetric 0002 peak (not shown), the cell parameters were determined. The film exhibited an $a$-axis of $3.1691 \AA$ and a $c$-axis of $3.5283 \AA$, which are very close to the literature values of 3.1687 and $3.5300 \AA$, respectively. These cell parameters determine an 
in-plane strain of 0.00013 and an out-of-plane strain of -0.00048 , i.e. the film can be considered to be strain-free.

TEM results in Fig. 4 a) demonstrate that the film grows as epitaxial columns from the film-substrate interface to the film-vacuum interface, which is in agreement with the high intensities of the $\mathrm{ZrB}_{2} 000 \ell$ peaks in Fig. 1. This type of microstructure has previously been observed by us for $\mathrm{ZrB}_{2}$ films grown on $4 \mathrm{H}-\mathrm{SiC}(0001)$ and $\mathrm{Si}(111)$ [21,24]. It can also be seen that the surface of the film is smooth, which is also supported by a bright silvery metallic luster of our films, seen upon visual inspection. In Fig. 4 c) a high-magnification image demonstrates the well-ordered film at the film-surface interface. The selected area electron diffraction (SAED) pattern shown in Fig. 4 b) confirms the results from the $\{10 \overline{1} 1\}$ pole figure measurements, i.e. the film consists of domains with two different in-plane epitaxial directions. From the plan-view STEM image in Fig. 5 a) it can be seen that the in-plane size of the columns is $\sim 10 \mathrm{~nm}$ in diameter and that the surface is smooth, supporting our results from cross-sectional TEM. The alternating bright and dark lines present in the low-magnification STEM image is a camera artefact present during analysis of highly ordered films.

EELS was utilized to investigate if there was any evidence of segregation of either Zr or B to the grain boundaries. In Fig. 5 c) two summarized EELS spectra from the areas marked in the EELS map in Fig. 5 b) can be seen, where one (grey) is taken from the grain boundary and the other (black) is recorded from the center of a grain. The analysis is complicated as the abrupt $\mathrm{K}$ edge of $\mathrm{B}$ at $188.0 \mathrm{eV}$ overlaps with the $\mathrm{Zr} \mathrm{M}_{4,5}$ peak with edge at $180.0 \mathrm{eV}$ and with these edge energies only accurate to about $-2 \mathrm{eV}$ to $+7 \mathrm{eV}$ due to chemical shifts [30]. The above conditions thus imply that the signal in the spectra originates from both $\mathrm{Zr}$ and B. However, as can be seen in Fig. 5c the peak in the spectrum recorded at the grain boundary (grey) is shifted slightly towards higher electron loss energies compared to the spectrum recorded from the grain (black). Given the higher electron loss energy of B compared to $\mathrm{Zr}$ this suggests a small excess 
of B at this grain boundary. Furthermore, the peak position $\sim 190$ to $\sim 200 \mathrm{eV}$ supports a chemical shift for the segregated B located in the grain boundary. Perhaps where the B has chemically reacted with an element of high electronegativity such as O. This type of reaction on the surface of epitaxial $\mathrm{ZrB}_{2}$ films is supported from X-ray photoelectron spectroscopy showing B-O bonding at $193 \mathrm{eV}$ prior to sputter cleaning [24]. There was no evidence of excess B in the more coherent grain boundaries. Fig. 6 a)-d) shows four examples of such semicoherent grain boundaries. The B segregation tendency was also shown by Mayrhofer et al [7] and Nedfors et al [31] found for 0001-oriented $\mathrm{TiB}_{2.4}$ films and randomly oriented $\mathrm{NbB}_{2-\mathrm{x}}$ films, respectively, who reported tissue phase in all grain-boundaries throughout the film. However, our processing shows that $\mathrm{ZrB}_{2}$ films can be produced with only slight excess $\mathrm{B}$ at isolated grain-boundaries, and not enough B to form a continuous tissue phase.

The resistivity of the films in this study was determined to between 125 and $200 \mu \Omega \mathrm{cm}$ regardless of thickness, which is substantially higher than the bulk value for $\mathrm{ZrB}_{2}$ ( $\sim 10 \mu \Omega \mathrm{cm}[2])$, but comparable to our epitaxial films previously deposited on $4 \mathrm{H}-\mathrm{SiC}(0001)$ [24]. As we discussed in a previous study [24], O impurities in the films could be a contributing reason for the film resistivity to be higher than bulk, but also the columnar microstructure is likely to affect the resistivity due to grain-boundary scattering.

\subsection{Mechanical properties}

Nanoindentation was used to assess the hardness, reduced Young's modulus, and elastic recovery of the films. In Fig. 7, a nanoindentation load-displacement curve with a maximum applied load of $8510 \mu \mathrm{N}$ is shown for a $1200 \mathrm{~nm}$ thick $\mathrm{ZrB}_{2}$ film. Two small pop-ins of $\sim 1 \mathrm{~nm}$ (marked with squares in the figure) can be seen and similar features appear in all load-displacement curves for maximum loads above $\sim 4750 \mu \mathrm{N}$. We suggest that the pop-ins 
are due to sudden activation of shear sliding of vertical domain boundaries observed for these films [32].

An SPM image of the indented area after 20 indentations in the same place, each with the maximum load of $2500 \mu \mathrm{N}$, can be seen in Fig. 8. The picture reveals that there is no evidence of pile-up. The triangular shapes seen in the image are due to a tip artifact because the radius of the Berkovich tip used to generate the image $(\sim 150 \mathrm{~nm})$ is larger than the roughness of the film. The small surface roughness is confirmed by the TEM images in Fig. 4 a) and Fig. 5 a). The lack of pile-up during indentation guarantee that the hardness values calculated by Oliver and Pharr's method are precise and do not need to be corrected.

All investigated films, with thicknesses of $400 \mathrm{~nm}$ or $1200 \mathrm{~nm}$, display hardness values above $45 \mathrm{GPa}$, thus exhibiting superhardness (defined as $\geq 40 \mathrm{GPa}$ [33]). The film hardness is about twice as high as that reported for bulk $\mathrm{ZrB}_{2}$ of $23 \mathrm{GPa}$ in the literature [1]. For a relevant comparison, we measured a polycrystalline $\mathrm{ZrB}_{2}$ bulk sample obtained by spark plasma sintering [34] using the same nanoindentation instrument and parameters as for our thin films. The bulk-sample hardness was determined to $31.1 \pm 2.9 \mathrm{GPa}$, thus showing that our films are much harder than bulk. The measured reduced Young's modulus of our films is in the range 350-400 GPa, comparable to $E_{r}=339 \pm 13 \mathrm{GPa}$ of the bulk sample.

For our in-depth characterization of the mechanical properties, we used the thicker films to minimize the influence of the substrate. The mechanical uniformity of a $1200 \mathrm{~nm}$ thick films across its thickness was investigated by performing 40 indents with increasing maximum loads in the range 510 to $9750 \mu \mathrm{N}$. The indentations were separated by $10 \mu \mathrm{m}$ to avoid any interference among measurements. Fig. 9 shows that $\mathrm{H}$ and $\mathrm{E}_{\mathrm{r}}$, plotted as a function of the maximum applied load and penetration depth, are constant in the range 1000-9750 $\mu \mathrm{N}$ (corresponding to 22-108 nm penetration depth). The result means that the "work hardening" 
(strengthening of the material under deformation) is constant in this load-range. Taking into consideration the high elasticity of the film discussed below, we can establish that the work hardening constant value will be very small [35]. The increase of $\mathrm{H}$ for penetration depths $<22 \mathrm{~nm}$ (marked in the figure) could be related to an indentation size effect [36], but more experimental work should be done to elucidate the origin of this increase.

The few available hardness studies of $\mathrm{ZrB}_{2}$ films have employed Vickers hardness measurements, making comparisons with our nanoindentation data difficult. Rau et al [11] report hardness values of between 21 and 27 GPa for $200 \mathrm{~nm}$ thick 1120-oriented pulsed laser deposited $\mathrm{ZrB}_{2}$ thin films, and values between 19 and $23 \mathrm{GPa}$ for amorphous $500 \mathrm{~nm}$ thick electron beam deposited films. Mitterer et al [12] have determined the hardness of their polycrystalline, magnetron sputtered films with thickness of 3-4 $\mu \mathrm{m}$ to be in the range 1700 to $2300 \mathrm{HV}$ ( 16-23 GPa), depending on argon flow rate and bias voltage. All these values are comparable to the bulk hardness. In contrast, Kelesoglu et al [13] report hardness values varying between 4150 and $5480 \mathrm{HV}$ ( 40-54 GPa) for magnetron sputtered films of 3-4 $\mu$ m thickness where the films with the highest hardness are 0001-oriented. Our epitaxial films are thus in the higher part of the hardness range reported for $\mathrm{ZrB}_{2}$ thin films, assuming that the two methods of hardness measurements are comparable.

To elucidate if $\mathrm{ZrB}_{2}$ thin films could be a contender to the related material, $\mathrm{TiB}_{2}$ in metal cutting applications and to discuss the relationship between obtained hardness values and film microstructure, we compared $\mathrm{ZrB}_{2}$ films with $\mathrm{TiB}_{2}$ thin films presented in the literature. The range of reported hardness values is large for $\mathrm{TiB}_{2}$ films. For example, Sanchez et al report hardness values of 15 GPa, i.e. considerably lower than the bulk hardness of $24 \mathrm{GPa}$ [3]. On the other hand several studies have reported superhard $\mathrm{TiB}_{2}$ films. Berger et al have demonstrated growth of 0001-oriented films with both high and low residual stresses, all with hardness values around $50 \mathrm{GPa}$ as determined by nanoindentation. In the previous mentioned 
study of Kelesoglu et al [13], hardness values of 3100-5480 HV ( 30-54 GPa) for $\mathrm{TiB}_{2}$ were reported, i.e. their $\mathrm{TiB}_{2}$ films exhibit lower or similar hardness values compared to their $\mathrm{ZrB}_{2}$ films investigated in the same study. Mayrhofer et al [7] have demonstrated growth of $\mathrm{TiB}_{2}$ films exhibiting hardness values of $60 \mathrm{GPa}$. They explain the observed superhardness in their overstochiometric 0001-textured $\mathrm{TiB}_{2.4}$ films to be related to two effects: 1 ) the short length of the primary dislocation planes due to the nanocolumnar structure of their films, making dislocation formation unlikely, and 2) an ultrathin B-rich tissue phase between the grains in their films, which would prevent any formed dislocations from moving. Furthermore, they state that the B in the tissue phase enhances the cohesive strength of the boundary regions, which usually have the lowest resistance to distortion during indentation. Nedfors et al [31] also attributes the observed superhardness in their non-textured substochiometric $\mathrm{NbB}_{2-\mathrm{x}}$ thin films to the small grain size $(5-10 \mathrm{~nm})$ hindering dislocation nucleation, and the presence of a B-rich tissue phase between the grains, hindering grain boundary sliding.

Our epitaxial $\mathrm{ZrB}_{2}$ films exhibit a domain structure with a size of approximately $10 \mathrm{~nm}$ in the $\mathrm{x}$ - and y-directions, but in contrast to the films deposited by Mayrhofer et al [7] and Nedfors et al [31], the grains are $1200 \mathrm{~nm}$ long in the z-direction. The 0001-orientation of our films are the same as the $\mathrm{TiB}_{2+\mathrm{x}}$ films [4,7], but differs from the $\mathrm{NbB}_{2-\mathrm{x}}$ films [31]. Also, in contrast to Mayrhofer et al [7] and Nedfors et al [31] we have much less excess B at otherwise semi-coherent domain boundaries and no evidence of a B-rich phase between all columns. Among various grain boundaries reported to form in $\mathrm{ZrB}_{2}$ films, our semi-coherent ones (see Fig 6) should have the strongest bonding and thus strength. Together, the large vertical coherence length in the film and the absence of a B-rich phase between the columns in our epitaxial films explain why there are no domain boundary sliding, as opposed to polycrystalline films from the literature that would be apt to slip on grain boundaries. 
There are two main glide systems for $\mathrm{ZrB}_{2}$, the basal glide $\{0001\}<11 \overline{2} 0>$ and the prismatic glide $\{1 \overline{1} 00\}<11 \overline{2} 0>$ [37]. For plastic deformation to occur, the material needs to be subjected to shear stress. Since our films are 0001-oriented and the force is applied normal to these planes, no shear force is projected directly on the basal planes, i.e. less dislocation movement would occur on the 0001 planes, and only so from any redistributed stress components. The small size of the columns in the $\mathrm{x}$ - and $\mathrm{y}$-directions is therefore of little influence. The prismatic planes are vertical, as are the majority of the grain boundaries in our films and deformation would cause the columns to move along the domain walls and be pushed down into the substrate rather than cause deformation diagonally across the columnar-like domains. Based on this we believe that the most important factor for the observed hardness of our films is the 0001-orientation.

From the unloading curve of the load-displacement curves, the $\mathrm{W}_{\mathrm{e}}$ was calculated. Fig. 10 shows that $\mathrm{W}_{\mathrm{e}}$ decreases from $\sim 100 \%$ to $\sim 70 \%$ when the applied load (penetration depth) increases from 510 to $9750 \mu \mathrm{N}$, i.e. the elasticity of the film remains high also at higher loads. This property has not been reported for borides films previously. A high elasticity combined with our report on high hardness are promising characteristics for the further development of borides as thin film materials.

Other insights for the high elasticity of the film is seen from an experiment when the hardness and reduced Young's modulus was measured 20 times in the same position using a maximum loading force of $2500 \mu \mathrm{N}$ (penetration depth of $\sim 40 \mathrm{~nm}$ ) (not shown). The slight decrease of $\mathrm{W}_{\mathrm{e}}$ from $95.5 \%$ in the first indent to $94.3 \%$ in the last indent shows that the elastic behavior is more or less constant after multiple indents.

Based on the mechanical properties of our $\mathrm{ZrB}_{2}$ thin films, compared to the properties of $\mathrm{TiB}_{2}$ thin films in the literature, we believe that $\mathrm{ZrB}_{2}$ could be a good contender to $\mathrm{TiB}_{2}$ thin films in applications such as metal cutting. 


\section{Conclusions}

Epitaxial $\mathrm{ZrB}_{2}(0001)$ thin films was deposited on $\mathrm{Al}_{2} \mathrm{O}_{3}(0001)$ substrates. The films have a domain structure with two in-plane epitaxial relationships to the substrate, $\mathrm{ZrB}_{2}[10 \overline{1} 0] \| \mathrm{Al}_{2} \mathrm{O}_{3}[10 \overline{1} 0]$ and $\mathrm{ZrB}_{2}[11 \overline{2} 0] \| \mathrm{Al}_{2} \mathrm{O}_{3}[10 \overline{1} 0]$. All films exhibit hardness values above $45 \mathrm{GPa}$, twice as high as for bulk $\mathrm{ZrB}_{2}$, and the reduced Young's modulus is in the range 350-400 GPa. In addition, the films exhibit high elastic recovery of $70 \%$ at an applied load of $9000 \mu \mathrm{N}$. The semi-coherent domain boundaries will likely uphold the films' mechanical strength. The mechanical properties of the $\mathrm{ZrB}_{2}$ thin films suggest that this material is a good contender to $\mathrm{TiB}_{2}$ in applications which require hard films, such as metal cutting.

\section{Acknowledgements}

This work was supported by the Swedish Research Council (VR) through the contract 621-2010-3921. EB and HH acknowledge financial support from the Swedish Government Strategic Research Area in Materials Science on Functional Materials at Linköping University (Faculty Grant SFO-Mat-LiU No. 2009-00971). The Knut and Alice Wallenberg Foundation supported our thin film and electron microscopy laboratories. The authors acknowledge Dr. Shu-Qi Guo, National Institute for Materials Science, Tsukuba (Japan) for providing a bulk $\mathrm{ZrB}_{2}$ sample for nanoindentation comparison.

\section{References}

[1] Fahrenholtz WG, Hilmas GE, Talmy IG, Zaykoski JA. Refractory diborides of zirconium and hafnium, J Am Ceram Soc 2007;90:1347.

[2] Rahman M, Wang CC, Chen W, Akbar SA, Mroz C. Electrical Resistivity of Titanium Diboride and Zirconium Diboride, J Am Ceram Soc 1995;78:1380.

[3] Munro RG. Material Properties of Titanium Diboride, Journal of Research of the National Institute of Standards and Technology 2000;105:709.

[4] Berger M, Karlsson L, Larsson M, Hogmark S. Low stress $\mathrm{TiB}_{2}$ coatings with improved tribological properties, Thin Solid Films 2001;401:179. 
[5] Kunc F, Musil J, Mayrhofer PH, Mitterer C. Low-stress superhard Ti-B films prepared by magnetron sputtering, Surface and Coatings Technology 2003;174-175:744.

[6] Mishra SK, Rupa PKP, Pathak LC. Surface and nanoindentation studies on nanocrystalline titanium diboride thin film deposited by magnetron sputtering, Thin Solid Films 2007;515:6884.

[7] Mayrhofer PH, Mitterer C, Wen JG, Greene JE, Petrov I. Self-organized nanocolumnar structure in superhard $\mathrm{TiB}_{2}$ thin films, Appl Phys Lett 2005;86:131909-1.

[8] Mikula M, Grančič B, Buršíková V, Csuba A, Držík M, Kavecký Š, Plecenik A, Kúš P. Mechanical properties of superhard $\mathrm{TiB}_{2}$ coatings prepared by $\mathrm{DC}$ magnetron sputtering, Vacuum 2007;82:278.

[9] Sanchez CMT, Plata BR, da Costa MEHM, Freire FL. Titanium diboride thin films produced by dc-magnetron sputtering: Structural and mechanical properties, Surface and Coatings Technology 2011;205:3698.

[10] Rupa PKP, Chakraborti PC, Mishra SK. Mechanical and deformation behaviour of titanium diboride thin films deposited by magnetron sputtering, Thin Solid Films 2009;517:2912.

[11] Rau JV, Ferro D, Falcone MB, Generosi A, Albertini VR, Latini A, Teghil R, Barinov SM. Hardness of zirconium diboride films deposited on titanium substrates, Mater.Chem.Phys. 2008;112:504.

[12] Mitterer C, Komenda-Stallmaier J, Losbichler P, Schmölz P, Werner WSM, Störi H. Sputter deposition of decorative boride coatings, Vacuum 1995;46:1281.

[13] Kelesoglu E, Mitterer C, Kazmanli MK, Ürgen M. Microstructure and properties of nitride and diboride hard coatings deposited under intense mild-energy ion bombardment, Surface and Coatings Technology 1999;116-119:133.

[14] X. Zou. Oxidation behavior of RF sputter deposited zirconium diboride thin films1995San Jose State University

[15] Wright JS, Khanna R, Ramani K, Cranciun V, Singh R, Norton DP, Pearton SJ, Ren F, Kravchenko II. ZrB2/Pt/Au Ohmic contacts on bulk, single-crystal ZnO, Appl Surf Sci 2006;253:2465.

[16] Mitterer C, Ubleis A, Ebner R. Sputter deposition of wear-resistant coatings within the system Zr-B-N, Mater Sci Eng A 1991;140:670.

[17] Shappirio JR, Finnegan JJ. Synthesis and properties of some refractory transition metal diboride thin films, Thin Solid Films 1983;107:81.

[18] Takeyama MB, Noya A, Nakadai Y, Kambara S, Hatanaka M, Hayasaka Y, Aoyagi E, Machida H, Masu K. Low temperature deposited Zr-B film applicable to extremely thin barrier for copper interconnect, Appl Surf Sci 2009;256:1222. 
[19] Brandstetter E, Mitterer C, Ebner R. A transmission electron microscopy study on sputtered Zr-B and Zr-B-N films, Thin Solid Films 1991;201:123.

[20] Tengdelius L, Samuelsson M, Jensen J, Lu J, Hultman L, Forsberg U, Janzén E, Högberg $\mathrm{H}$. Direct current magnetron sputtered $\mathrm{ZrB}_{2}$ thin films on $4 \mathrm{H}-\mathrm{SiC}(0001)$ and $\mathrm{Si}(100)$, Thin Solid Films 2014;550:285.

[21] Tengdelius L, Birch J, Lu J, Hultman L, Forsberg U, Janzén E, Högberg H. Magnetron sputtering of epitaxial $\mathrm{ZrB}_{2}$ thin films on $4 \mathrm{H}-\mathrm{SiC}(0001)$ and $\mathrm{Si}(111)$, Phys Status Solidi A 2014;211:636.

[22] Chakrabarti UK, Barz H, Dautremont-Smith WC, Lee JW, Kometani TY. Deposition of zirconium boride thin films by direct current triode sputtering, J Vac Sci Technol A 1987;5:196.

[23] Khanna R, Ramani K, Cracium V, Singh R, Pearton SJ, Ren F, Kravchenko II. ZrB 2 Schottky diode contacts on n-GaN, Appl Surf Sci 2006;253:2315.

[24] Tengdelius L, Greczynski G, Chubarov M, Lu J, Forsberg U, Hultman L, Janzén E, Högberg H. Stoichiometric, epitaxial $\mathrm{ZrB}_{2}$ thin films with low oxygen-content deposited by magnetron sputtering from a compound target: Effects of deposition temperature and sputtering power, J.Cryst.Growth 2015;430:55.

[25] Birch J, Sundgren J-E, Fewster PF. Measurement of the lattice parameters in the individual layers of single-crystal superlattices, J.Appl.Phys. 1995;78:6562.

[26] Fewster PF. Reciprocal space mapping, Critical Reviews in Solid State and Materials Sciences 1997;22:69.

[27] Oliver WC, Pharr GM. Measurement of hardness and elastic modulus by instrumented indentation: Advances in understanding and refinements to methodology, J.Mater.Res. 2004;19:3.

[28] Musil J, Kunc F, Zeman H, Poláková H. Relationships between hardness, Young's modulus and elastic recovery in hard nanocomposite coatings, Surface and Coatings Technology 2002;154:304.

[29] Bera S, Sumiyoshi Y, Yamada-Takamura Y. Growth of single-crystalline zirconium diboride thin film on sapphire, J.Appl.Phys. 2009;106

[30] Ahn C, Krivanek O, Burgner R, Disko M, Swann P. EELS Atlas Gatan Inc, Warrendale, PA 1983

[31] Nedfors N, Tengstrand O, Lu J, Eklund P, Persson POA, Hultman L, Jansson U. Superhard $\mathrm{NbB}_{2-\mathrm{x}}$ thin films deposited by dc magnetron sputtering, Surf Coat Technol 2014;257:295.

[32] Jian S, Chen G-, Chen H-, Jang JS-, Liao Y-, Yang P-, Lai Y-, Chen M-, Kao H-, Juang J-. Cross-sectional transmission electron microscopy studies for deformation behaviors of 
AlN thin films under Berkovich nanoindentation, J.Alloys Compounds 2010;504, Supplement 1:S395.

[33] Veprek S. The search for novel, superhard materials, J.Vac.Sci.Technol.A Vac.Surf.Films 1999;17:2401.

[34] Guo S-Q, Nishimura T, Kagawa Y, Yang J-M. Spark plasma sintering of zirconium diborides, J Am Ceram Soc 2008;91:2848.

[35] Mayrhofer PH, Mitterer C, Hultman L, Clemens H. Microstructural design of hard coatings, Progress in Materials Science 2006;51:1032.

[36] Veprek S, Mukherjee S, Karvankova P, Männling H-D, He JL, Moto K, Prochazka J, Argon AS. Hertzian analysis of the self-consistency and reliability of the indentation hardness measurements on superhard nanocomposite coatings, Thin Solid Films 2003;436:220.

[37] Matkovich VI. Boron and Refractory Borides. New York: Springer-Verlag Berlin Heidelberg, 1977. 


\section{Figure captions}

Figure 1. X-ray $\theta / 2 \theta$ scan of a $\mathrm{ZrB}_{2}$ film. The inset displays the same $\theta / 2 \theta$ scan using a linear intensity scale.

Figure 2. XRD pole figures showing a) the $\{10 \overline{1} 1\}$ pole figure of a $\mathrm{ZrB}_{2}$ film and b) the $\{10 \overline{1} 4\}$ pole figure of the $\mathrm{Al}_{2} \mathrm{O}_{3}$ substrate. Color online.

Figure 3. RSM of the $\mathrm{ZrB}_{2} 10 \overline{1} 3$ lattice point. Color online.

Figure 4. a) Low-magnification TEM overview image of a cross-section of a $\mathrm{ZrB}_{2}$ film, b) SAED pattern, and c) high-magnification TEM image from the film-substrate interface.

Figure 5. a) Low-magnification STEM overview image of a $\mathrm{ZrB}_{2}$ film surface, b) Z-contrast image recorded on the surface of the film, and c) EELS spectra from the two areas indicated in Fig. 5(b) where the grey is from a grain boundary and the black from inside a grain.

Figure 6. Z-contrast images of four (a)-d)) semi-coherent grain-boundaries on a $\mathrm{ZrB}_{2}$ film surface

Figure 7. Nanoindentation load-displacement curve with a maximum applied load of $8510 \mu N$. Pop-ins are marked by squares in the figure.

Figure 8. SPM image of a $\mathrm{ZrB}_{2}$ film showing the indentation imprint area after 20 indentations in the same place, each with the maximum load of $2500 \mu \mathrm{N}$. Color online.

Figure 9. Hardness, $\mathrm{H}$, and reduced Young's modulus, $\mathrm{E}_{\mathrm{r}}$, values plotted against maximum applied load and tip penetration depth for a $\mathrm{ZrB}_{2}$ film. The dashed line marks the penetration depth of $22 \mathrm{~nm}$, below which the increase of $\mathrm{H}$ can be related to an indentation size effect.

Figure 10. Elastic recovery, $\mathrm{W}_{\mathrm{e}}$, values plotted against maximum applied load and tip penetration depth for a $\mathrm{ZrB}_{2}$ film. 


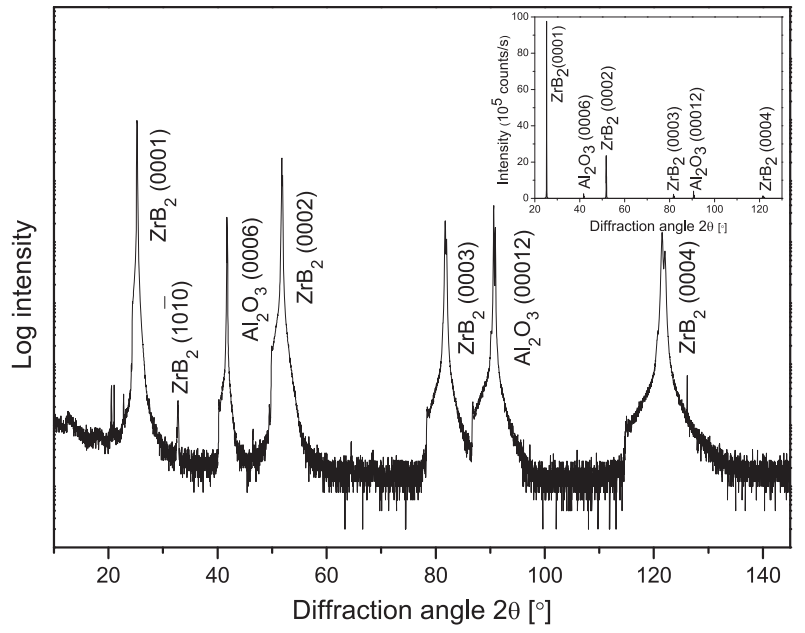


a)

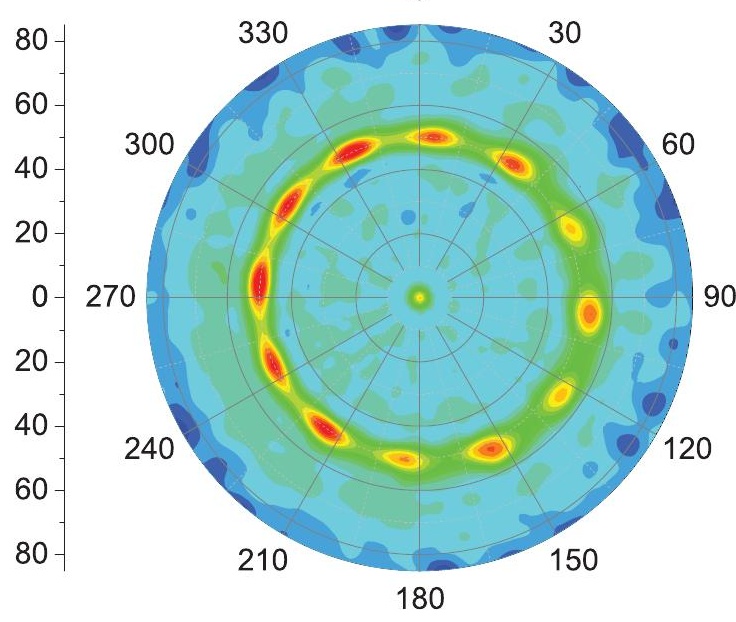

Angle $\varphi\left[{ }^{\circ}\right]$

b)

0

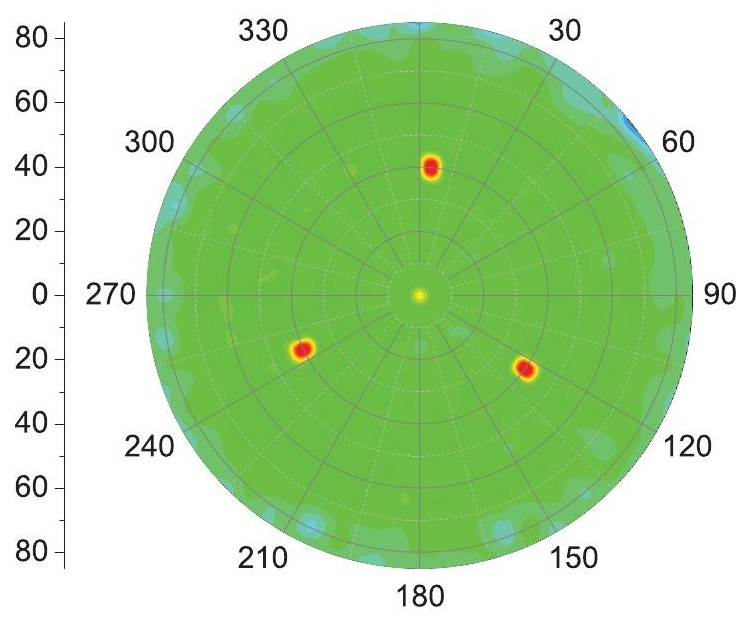

Angle $\varphi\left[{ }^{\circ}\right]$ 


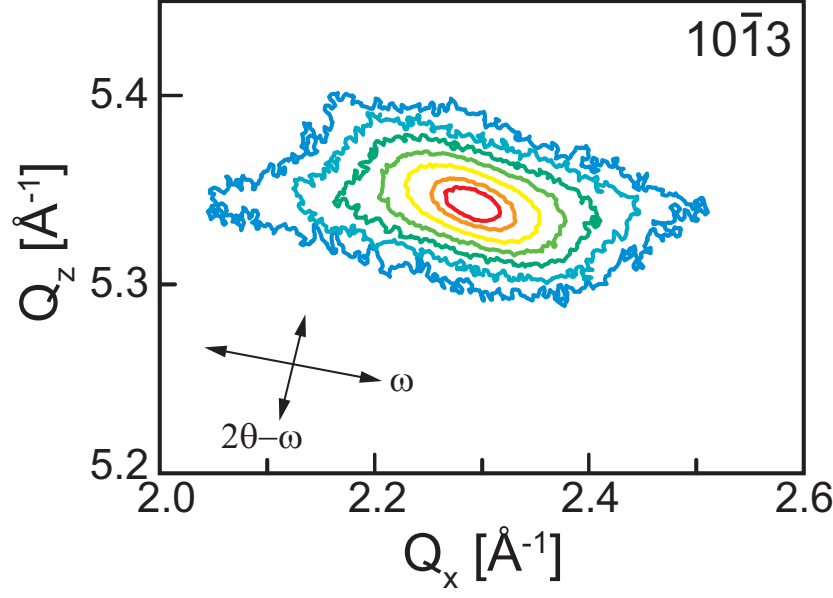




\section{a)}

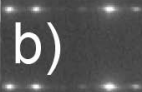

0001
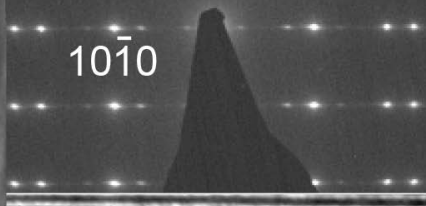

\section{(

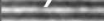



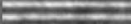

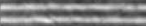

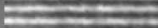

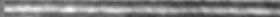

\section{sens}

teras

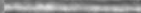

rases

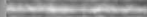



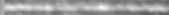

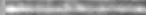

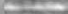

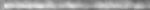

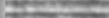

$\mathrm{ZrB}_{2}(0001)$

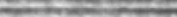

(2)

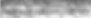

\section{$\mathrm{Al}_{2} \mathrm{O}_{3}(0001)$}

\section{$100 \mathrm{~nm}$}

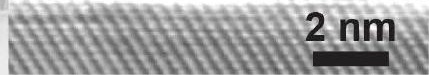









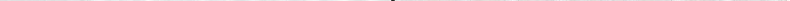







$15.8 \mathrm{~nm}$

$1 \mu \mathrm{m}$

$7.9 \mathrm{~nm}$

$0.0 \mathrm{~nm}$ 


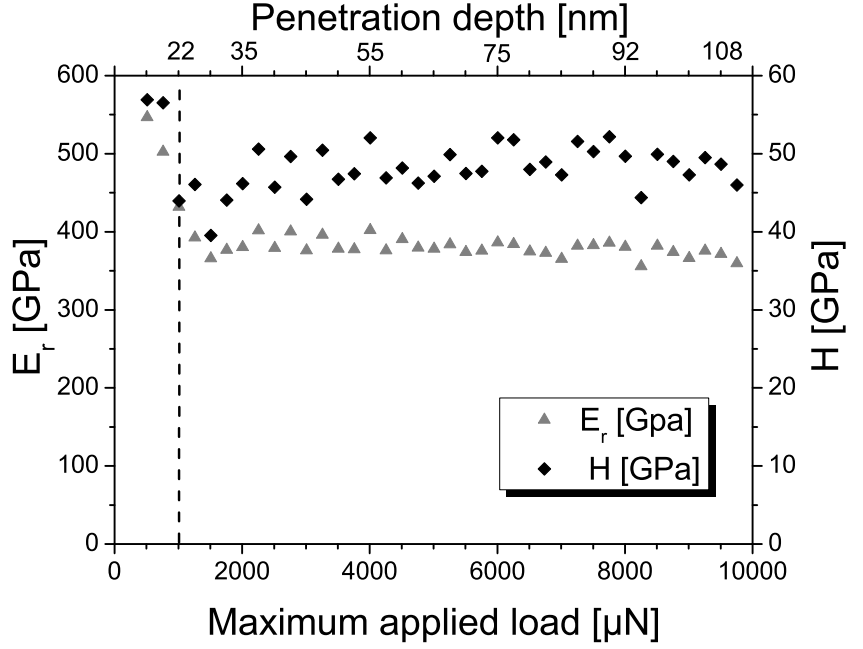


Penetration depth [nm]

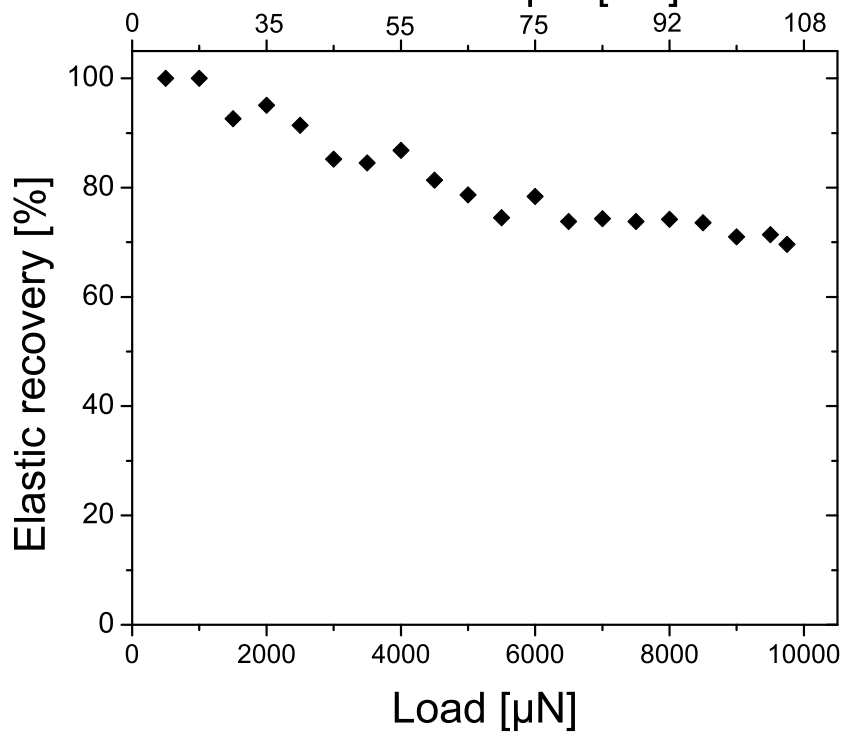

